\title{
Dinamik Kontrollü Uyarlanabilir Cephe ve Gölgeleme Sistemleri
}

\author{
Büşra YAMAN ${ }^{1 *(D)}$, Ümit Turgay ARPACIOĞLU ${ }^{2}$ (iD \\ ORCID 1: 0000-0001-7457-3942 \\ ORCID 2: 0000-0001-8858-7499 \\ ${ }^{1}$ Mimar Sinan Güzel Sanatlar Üniversitesi, Fen Bilimleri Enstitüsü, Yapı Fiziği ve Malzemesi Ana Bilim Dalı, \\ 34427, Istanbul, Türkiye \\ ${ }^{2}$ Mimar Sinan Güzel Sanatlar Üniversitesi, Mimarlık Fakültesi, Yapı Fiziği ve Malzemesi Ana Bilim Dalı, 34427, \\ Istanbul, Türkiye \\ Öz \\ *e-mail: yamannbusra@gmail.com \\ Uyarlanabilir cepheler, bina enerji kullanımı ve $\mathrm{CO}_{2}$ emisyonlarında önemli miktarda tasarruf sağlarken, aynı \\ zamanda iç ortamın kalitesi üzerinde olumlu bir etkiye sahiptir. Farklı uyarlanabilir cephe konseptleri (malzemeler, \\ bileşenler ve sistemler) yenilikçi çözümler ile geliştirilmeye devam etmektedir. Bu makalenin amacı, uyarlanabilir \\ cephe konseptlerini sınıflandırarak gelişmelere katkıda bulunmaktır. Dinamik kontrollü uyarlanabilir bina cephesi, \\ değişken ortam koşullarına adapte olabilen dinamik cepheler için kullanılan bir kavramdır. Teknoloji ile gelişmekte \\ olan bina bileşenleri ve sistemleri aracılığıla cephe tasarım parametrelerine göre termal konfor ve enerji \\ performansını sağlamak için bina enerji verimliliğinde iyileştirmeler sağlanması hedeflenmektedir. Makro veya \\ mikro ölçekte uyarlanabilir gölgeleme sistemleri, özelliklerin veya davranışların değişmesine dayanır. \\ Uyarlanabilir gölgeleme sistemleri diğer sistemlerle etkileşimli olarak tasarlanabilir. Bu makalenin amacı, mevcut \\ kavramların analizinden yola çıkıp yeni bir yaklaşım önererek bu gelişmelere katkıda bulunmaktır.
}

Anahtar Kelimeler: Uyarlanabilirlik, gölgeleme sistemleri, akıllı malzeme, enerji performansı, termal konfor

\section{Dynamically Controlled Adaptive Facade and Shading Systems}

\begin{abstract}
While the usable facades provide significant savings in building energy use and $\mathrm{CO}_{2}$ emissions, it also has a beneficial effect on the quality of the indoor environment. Different adaptable facade concepts (materials, components and systems) continue to be developed with innovative solutions. The purpose of this article is to use adaptive façade concepts in classification practice. Dynamic dynamically adaptive building is a concept used for dynamic facades that can adapt to a variable environment. It is aimed to improve building energy efficiency in order to obtain thermal comfort and energy according to the green facade design parameters of developing buildings and systems with technology. Macro or micro adaptive shading systems rely on changing properties or behaviors. Adaptive shading systems can be designed interactively with other systems. The aim of this article is to present a new application based on the analysis of existing concepts.
\end{abstract}

Keywords: Adaptability, shading systems, smart material, energy performance, thermal comfort

Atıf/Citation: Yaman, B, Arpacıoğlu, Ü. T. (2021). Dinamik Kontrollü Uyarlanabilir Cephe ve Gölgeleme Sistemleri. Journal of Architectural Sciences and Applications, 6 (1), 153-164. DOI: 10.30785/mbud.798233 


\section{Giriş}

Enerji performansını ve iç mekân konforunu iyileştirmek için çağdaş mimaride, cephe tasarımını statikten dinamiğe dönüştürme ile ilgili çalışmalar devam etmektedir. Binaların enerji verimliliğini artırmak için malzeme, konsept ve teknolojinin geliştirilmesi amacına ulaşmak için dinamik sistem tasarımına önem verilmektedir. Uyarlanabilir (Adaptive) mimarinin tanımı ilk kez şekil, konum, kullanım veya boyut değiştirebilen bir sistem olarak Frei Otto tarafından tanımlanmıştır (Ergin, 2019). Dinamik cephelerin tasarlanması konusu son yıllarda ciddi bir araştırma konusu haline gelmiştir. Dinamik kontrollü uyarlanabilir bina cephesi, değişken ortam koşullarına adapte olabilen dinamik cepheler için kullanılan bir kavramdır. 'Akıllı', 'kinetik', 'akıllı', 'aktif' vb. gibi 'dinamik' ve 'uyarlanabilir' terimlerinin çeşitli varyantları vardır. Her terimin anlamı farklı olsa da, bunlar genellikle birbirlerinin yerine kullanılır.

Mimari yapının uyarlanabilir olmasında en önemli katkıyı sağlayan yapı elemanlarından birisi cephelerdir. Binalar, iklimsel değişimler ile cephelerini bunlara adapte olabilmesini gerekli kılmaktadır. Küresel ısınma nedeniyle binalar ve kullanıcılar değişken iklimsel koşullara maruz kalmaktadır. Binanın iç ve dış uyumunun sağlanmasında, cephelerin ve bina kabuklarının kurguları, binaların yaşam süreçlerinde önemli yer tutmaktadır. Konfor seviyesinin optimum düzeye çıkartılarak, sistemin işlevselliği ile statik binalara göre daha fazla enerji verimliliği ve kullanıcı konforu sunabilmektedir. Binalara etki eden iklim ve enerji gibi etkenlerin sabit olmadı̆̆ı, değişken ve geçici olduğu bilinerek bina cephesi tasarım konsepti, bir kabuk olmaktan çıkarak farklı roller üstlenmektedir (Ergin, 2019).

Dinamik cephelerin avantajları; kullanıcıya konfor sağlaması, bina ömrünün uzaması, işletim maliyetlerinin azalması ve farklı konseptlere olanak tanıması gibi düşünülebilir. Çevre açısından avantajları ise; hava kirliliğinin azaltılması, sürdürülebilirliğin sağlanmasıdır. Enerjinin etkin kullanımı, çevre koşullarına uyum sağlayabilen, uyarlanabilir bina cephe sistemlerinin geliştirilmesinde farklı alternatifler ortaya çıkmasına zemin oluşturmaktadır. Uyarlanabilir bina cephesi oluşturmak için teknolojik gelişmelerin yapıya hangi parametrelerde entegre edilebileceği ve tasarlanması gerektiği, böylece termal konforun hangi koşullarda sağlandığı bu çalışmanın amacını oluşturmaktadır. 'Statik' cephe olarak bilinen geleneksel cephelerin hava şartlarındaki değişikliklere ve kullanıcı taleplerine uyum sağlamadığı kabul edilmektedir. Dinamik bina cephe tasarımcıları, uyarlanabilir gölgeleme sistemleri ile donatılmış şeffaf bir binanın 'statik' olarak kabul edilemeyeceğini savunurlar (Hraska, 2019). Bu gölgeleme sistemleri, uygun biçimde binaya entegre edildiklerinde çok çeşitli çevresel değişikliklere yanıt verebilir. Literatür taramasında, uyarlanabilir gölgeleme sistemlerinden bazılarının güneşten korunmada veya binanın enerji dengesini iyileştirmede daha iyi performans gösterdiğini belirtilmektedir. Bazı gölgeleme sistemleri de parlamanın ortadan kaldııılmasında veya gün ışığının dağıtılmasında daha iyi performans göstermektedir. Bu çalışmanın temel amacı, uyarlanabilir gölgeleme sistemlerinin sınıflandııımasını sağlamaktır. Cepheler yapının ana unsurudur, dış ve iş ortamlar arasındaki bir sınırdır. Termal konfor koşulları sadece dış çevresel faktörlere değil, binanın konumu ve yönü, cephe malzemeleri, gölgeleme cihazları gibi mimari parametrelere ve tasarım öğelerine de bağlıdır. Bu nedenle, binanın tasarım sürecinde cephelerin tasarımı ve seçimi, iç mekan ortamlarında görsel ve termal duyumların kalitesini desteklemek için önemli görevlerden biri olarak düşünülmelidir.

\section{Yöntem}

Bu araştırmanın değerlendirilmesinde tarama modeli kullanılmıştır. Örnek projelerden toplanan veriler kullanılarak konu-kapsam ve araştırmanın amacı doğrultusunda birincil ve ikincil kaynaklar kullanılarak çalışma alanı literatür taraması ile zenginleştirilmiştir.

Çalışmanın literatür özeti; farklı uyarlanabilir cephe konseptlerini sınıflandırarak gelişmelere katkıda bulunmaya zemin hazırlayacak çalışmaların taranması ve mevcut kavramların analizini gerçekleştirerek yeni bir yaklaşım yönteminin incelenmesini kapsamaktadır. Bu sistemlerin örnek proje üzerinden değerlendirilmesi çalışmanın sonraki aşamasını oluşturur. Çalışma sonucunda, makro ve mikro ölçekte gölgeleme sistemlerinin tasarım parametrelerine göre davranışlarının incelenmesi ve değerlendirilerek yeni yaklaşım önerileri sunulması hedeflenmektedir. 


\section{Bulgular ve Tartışma}

\subsection{Dinamik Kontrollü Uyarlanabilir Cephe Gereklilikleri}

Dinamik cepheyle entegreli binalar dış ortamın sürekli değişikliklerine uyum sağlayacak şekilde tasarlanmıştır. Bu değişikliklere örnek verilecek olursa, günlük veya yıllık olarak gerçekleşen, bulutlu veya güneşli havada iç mekana daha çok günışı̆̆ girmesini sağlayacak şekilde uzayan veya kısalan gölgeleme sistemi tasarlanabilir. Dinamik cepheli binalar sadece statik binalardan daha iyi performans sunmakla kalmamakla birlikte, aynı zamanda estetik bir görünüm de kazandıracaktır. Dinamik kontrollü cephelerin tanımını Loonen ve ark. "iklime uyum sağlayan bir cephe, değişen performans gereksinimlerine ve değişken sınır koşullarına yanıt olarak zaman içinde bazı işlevlerini, özelliklerini veya davranışlarını tekrar tekrar ve geri dönüşümlü olarak değiştirme yeteneğine sahiptir ve bunu genel bina performansını iyileştirmek amacıyla yapar." şeklinde tanımlamıştır. Bu tanımdan yola çıkarak uyarlanabilir cephelerin iç ortama günışığı sağlamak, termal konfor sağlamak, ısıtmak, soğutmak, termal ve elektrik enerjisini depolamak gibi işlevlerinin olduğu saptanmıştır. Uyarlanabilir binalara ve sistemlere duyulan ihtiyaç uzun zamandır bilinmektedir ve 'FACET' gibi bazı araştırma projesine tabi tutulmuştur. FACET projesinin amacı, iç ve dış ortam koşullarına yanıt olarak ısıtma, soğutma, havalandırma ve aydınlatma için enerji kullanımını minimuma indirmek amacıyla uyarlanabilir termal özelliklere sahip cepheleri araştırmaktır (Boer et al., 2011). Dinamik kontrollü uyarlanabilir cephe gereklilikleri, gölgeleme sistemi ve tasarım stratejileri ile enerji verimliliği olarak iki kısımda toparlanmıştır.

\subsubsection{Gölgeleme Sistemi ve Tasarım Stratejileri}

İnsan vücudunun sıcaklığını korumak gibi biyolojik süreçleri yansıtma girişimi olan gölgeleme sistemlerinin iç mekan sıcaklığını kontrol etmek en temel görevidir. Bu amaçla geliştirilmeye devam edilen gölgeleme sistemlerinin yapıya özgü tasarım statejisi de farklılık gösterebilmektedir. En bilinen gölgeleme elemanlarının yatay ve dikey entegre elemanlarından oluştuğunu görmekteyiz. Günümüzde gölgeleme sistemleri farklı bir yaklaşım ile ele alınmaktadır. Örneğin; Buckminster Fuller tarafından ABD'nin Expo'67 Pavyonu olarak tasarlanan jeodezik kubbe, içindeki yapılar için yapay bir iklim yaratmaktadır. Fuller'in tasarladığı bu yapıt, mimari bir başarı olarak teknoloji ile idealleşen bir tasarım statejisini ortaya koymaktadır. Tamamen akrilik panellerle kaplanan strüktürün mekan içi ısı ve ışık denetimi ise, bilgisayarla yönetilen ve güneş ışınlarının doğrultusuna göre hareket eden gölgeleme elemanları ile sağlanmıştır. İç mekanda aşırı ısınmayı önlemek için, üst panellerde havalandırma delikleri yer almaktadır.

\subsubsection{Bina enerji verimliliği}

Teknolojideki gelişmeyle birlikte, binalarda mekanik ve elektrikli ekipmanı kontrol eden bina yönetim sistemleri (BMS) yaygınlaşmıştır. Cepheler birçok senaryoya yanıt verecek çeşitli parametreleri karşılayacak stratejiler ile tasarlanmalıdır (Nady, 2017). Binaların enerji talebini yönetmek amacı ile geliştirilen bu teknoloji, binanın ısı yüklerini etkileyecek bina içi termal performansı iyileştirecek kinetik bileşenleri cepheye entegre etmek üzerine yoğunlaşmıştır. Elektronik olarak kontrol edilen, mekanik olarak aktive edilen gölgeleme sistemleri, kinetik veya dinamik yüksek performanslı bina cephe konseptini oluşturmaktadır. Böylece, binaların sürekli değişen çevresel koşullara dinamik bir şekilde yanıt vermesi ve bunu enerji verimli şekillerde yapma imkanı oluşarak uyarlanabilir bina cephesi kavramı günümüzde gelişen teknolojiyle birlikte yaygınlaşmıştır. Asıl amaç, uyarlanabilir cephelerin tasarımında enerji akışını daha iyi yönetmek, binanın performansını ve kullanıcı konforunu iyileştirmektir. Bina cephesinin bir enerji kaynağı olma olasılığı da vardır. Fotovoltaikler aynı anda güç üretmek ve bir binayı gölgelemek için cephelere entegre edilebilir. Bina cephesinin potansiyeli, sürdürülebilir geleceğe yönelik mimarinin gelişimindeki ilerlemeleri teşvik etmek için yapısal, işlevsel, estetik ve ekolojik perspektiflerden anlaşılmalıdır.

\subsection{Dinamik Uyarlanabilir Cephe Kavramı ve Parametreleri}

Bina cepheleri tasarlanırken dikkat edilmesi gereken bazı parametreler vardır. Her parametrenin o yapının karakterini tanımlama ve etkileme potansiyeli vardır. Bina içi termal ve görsel konfor düzeyi cepheden giren güneş ışığının kontrolüne bağlıdır. Yani içeriye giren ışık miktarı ile iç ortam sıcaklığı 
doğru orantılıdır. Bu durumda, gölgeme elemanları, güneş ışığını kısıtlamak için uygulanan en basit yöntem olarak kabul edilir ve güneş stratejisini cephe ile kurgulamaktadır. Aynı zamanda, hava sirkülasyonuna izin veren bina cephelerinde temiz havayı yönlendiren mekanik sistemler kullanılabilir. Böylece hava değişimi açısından yapı kabuğu önemli bir rol oynamaktadır. Çeşitli çevresel parametreler iç mekânların kalitesini ve kullanıcının memnuniyetini etkileyebilir. Bu nedenle, araştırmacıların çoğu çevrelerin termal yönlerine ve bina içindeki insan termal konforunun durumuna odaklanmaktadır.

\subsubsection{Termal konfor için etkileşim}

Uyarlanabilir cepheler, konfor koşullarını ve bina enerji performansını dengelemeye çalışan kontrollü araçlardır. En basit bilinen gölgeleme elemanı olarak jaluziler, statik gölgeleme cihazına göre daha iyi termal performansa sahiptir. Aynı zamanda hem soğutma yüklerinde hem de aydınlatma enerjisinde tasarruf sağlamaktadırlar. İç mekân çevre kalitesi bina düzeyinde değerlendirildiğinde, çoğu araştırmacı ortamların termal yönlerine ve bina içindeki insan termal konfor seviyesine odaklanmaktadır. Termal konfor koşulları yalnızca dış çevresel faktörlere (hava sıcaklığı, hava hareketi, güneş radyasyonu) değil, aynı zamanda temel olarak tasarım parametrelerine, binanın konumu ve yönü, cephe malzemeleri ve gölgeleme cihazlarına bağlıdır (Nady, 2017). Cephe davranışı, gölgeleme bileşenleri aracılığıyla iç mekân ve dış ortam parametrelerine göre değişebilme ve termal konfor ile birlikte enerji verimliliği ve ekonomisini geliştirebilme yeteneğine sahip olmalıdır. Bina tasarım sürecinde cephelerin tasarımı, iç ortamlarda görsel ve termal konfor kalitesini iyileştirmek için ana unsurlardan biri olarak kabul edilmelidir.

\subsubsection{Enerji performansı için etkileşim}

iklim değişikliği, iç mekanlarda enerji kullanımı ve insan konforu üzerinde olumlu etkileri olan yeni sistemlere olan ihtiyacı arttırmıştır (Alhazzaa, 2019). Konut ve ticari binalar, toplam enerji tüketiminin yaklaşık üçte birinden sorumlu tutulmaktadır. Struck ve diğ. (2015), uyarlanabilir cephe konseptine 'Bomb blast' olarak adlandırılan cephelerin dayanması gereken yüksek darbe kuvvetlerine sahip şok dalgaları ile karakterize edilen anlık yük değişimine dinamik olarak yanıt vermesi gerektiğini değerlendirmişlerdir. Bunun için esnek cephe bileşenlerinin aero elastic sönümlemesi gerekmektedir. New York'taki Dünya Ticaret Merkezi Tower 3 için öneri tasarım projesinin amacı, cephe elemanlarının bağlantılarının plastik deformasyon yoluyla daha yüksek enerji paylarını dağıtmaktı. Böylece ekip, bağlantı güçlerini birincil yapıyla sınırlandırmak için yapısal sisteme dönüşen 'patlama yükleri' için belirli bir sigorta bağlantıları geliştirmiştir. Bina, klasik yükler karşısında yıllık harcadığı enerjinin büyük kısmında tasarruf etmiş olmuştur.

\subsection{Dinamik Kontrollü Uyarlanabilir Cephe Sistemlerinin Sınıflandırılması}

Çalışmanın bu bölümü, uyarlanabilir cephelerin sınıflandırma stratejilerine odaklanmaktadır. Literatürde sınıflandırma biçimlerinin nasıl adapte edildiğine dair bazı çalışmalardan yola çıkarak bu bölüm oluşturulmuştur. Makalenin sonraki bölümlerinde daha detaylı açıklanacak olan cephe mekanizmaları, şekil, boyut, konum ve bazı özellikleri, teknolojinin gelişmesiyle beraber dinamik olarak değişebilmektedir. Dinamik bina kabuğu, mekanik olarak sistemin hareketli, döndürülebilir, genişletilip küçültülebilir olarak farklı çalıştırma yöntemleri ile tasarlanabilmektedir. 'Sıfır enerjili' dinamik bina cephe tasarımı ile malzeme tabanlı bir takım çalışmalar devam edilmektedir. Mikro ve makro ölçekte gölgeleme etkisi bulunduran bu sistemlerin amacı enerji performans düzeyini en optimum düzeye getirebilmektir. Dinamik cephe sistemlerinin tasarımı ve geliştirilmesi alt gruplara ayrılarak tanımlanmıştır. Son zamanlarda yayınlanan makaleler incelendiğinde, sınıflandırma yaklaşımlarının çeşitliliği farklı kavramlar arasındaki ilişkileri tanımlamaktadır. Bu tanımların ortak noktası, çevresel ve kullanıcı etkilerine göre farklı biçimlerde ve özellikler ile uyarlanabilir olmasıdır (Ergin, 2019). Böylece yüksek potansiyele sahip yenilikçi uyarlanabilir cephe bileşenlerinin daha da geliştirilmesinin hedeflendiği görülmektedir. Farklı araştırmacılar tarafından genel olarak dinamik cepheler üç ana aşamadan oluşmaktadır. Ilı aşama, bina çevresi hakkında bilgi toplamadır. Daha sonra elde edilen bilgilerin hesaplama, tasarlama ve kontrol edilmesi aşaması tamamlanır. Ve sonuncusu, iç-dış ortam koşullarına göre cephede kinetisizm, dönüştürme, katlanarak ve kaydırarak genişletme gibi fiziksel eylemler gerçekleştirme aşamasıdır. Örneğin; Addington ve Schodek, Ramzy ve Fayed'nin sınıflandırmaları kinetik mimariyi, bina bileşenlerinde değişken konum olarak tanımlamış, yöntem, 
kontrol tipi ve mekanizma olarak alt kategori şeklinde sınıflandırmıştır (Loonen et al., 2015). Ochoa ve Capeluto (2008), dinamik kontrollü cephe sistemlerinin aktif özelliklerinin, binaların iç veya dış ortamları için değişikliklere göre kendini ayarladığı bileşenler olarak tanımlamıştır. Daha çok sisteme odaklanarak, ISı, ışık, güneş ışığı gibi tasarım değişkenlerine sahip sensörler; gölgeleme, Isı, ışık, havalandırma ve enerji kontrol gibi tasarım değişkenlerine sahip kontrol elemanları gibi daha küçük alt gruplara ayırmıştır. Literatürdeki bu analizler ile terminoloji açısından ortak bir dil tutturmanın zor olduğunu ve uyarlanabilir cepheler için genel geçerliliği olan bazı unsurların kabul edildiğini gözlemleyebiliriz. Literatürde rastlanan bazı çalışmalar, mevcut yaklaşımların güçlü unsurlarını temel alarak daha önceki sınıflandırmalar ile geliştirilmektedir. Loonen ve diğerleri'ne (2015) göre, uyarlanabilir cephe sistemlerinde sınıflandırma planı geçmiş materyal ve bileşenlerini de barındırarak geleceğe dönük olmalı ve yeni teknolojilerin gelişimini teşvik edebilecek detaylarla yeteri kadar spesifik olmalıdır. Genellikle bu cephe kontrolü, bina yönetim sistemi aracılığıyla sensörler aracılığıyla diğer bina sistemlerine entegre edilir (Roy, 2018).

\subsubsection{GSW Headquarters, Berlin (1999)}

Uyarlanabilir sistem: Dinamik cephe, kullanıcı kontrollü akıllı yüzeyler

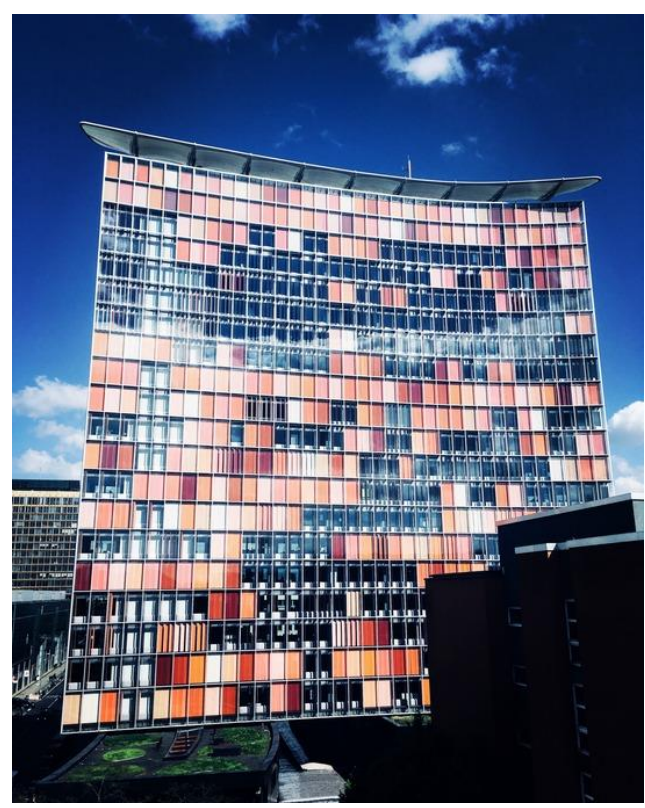

Şekil 1. GSW Headquarters Batı Cephesi

Şekil 1'de GSW Headquarters binasının en belirgin özelliği, sıcak havayı çapraz havalandırma yoluyla dışarı atarak binayı havalandıran ve aynı zamanda termal ve akustik varyasyonlara imkan veren çift katmanlı cephesi görülmektedir. Binanın doğu cephesinde camlar arasında otomatik veya manuel olarak çalıştırılabilen panjurlu üç camlı pencereler bulunmaktadır. Şekil 2'de görüldüğü gibi dış güneş gölgeleme sağlayan bu ara boşlukta, dikey alüminyum panjurlar yer almaktadır.

Bu sistem, üstte ve altta bulunan damperleri kapatıp açarak hava akışını ve mevcut gün ışığına göre yapay aydınlatmayı da kontrol eder. Sıcak havalarda çapraz havalandırma ile bina içinde sirkülasyon sağladığı Şekil 3'te görülmektedir. Soğuk aylarda, cephe tamamen kapatıldığında, termal tampon görevi görerek üst düzey verimlilik sağlanır. 


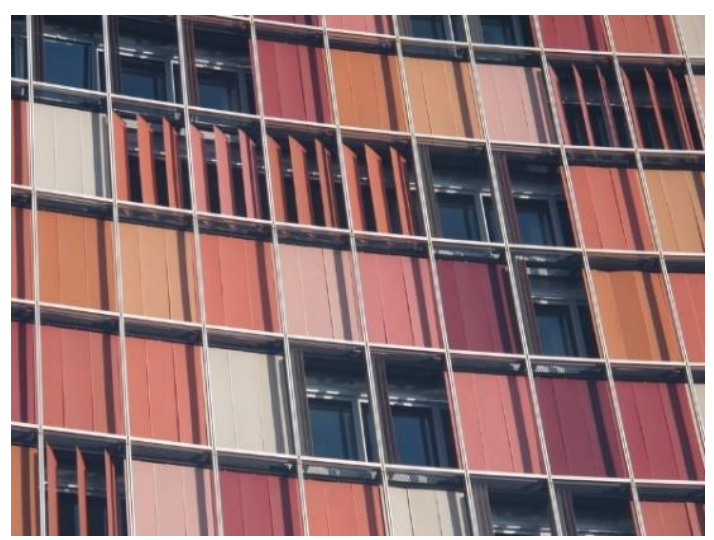

Şekil 2. Otomatik kontrollü gölgeleme elemanı

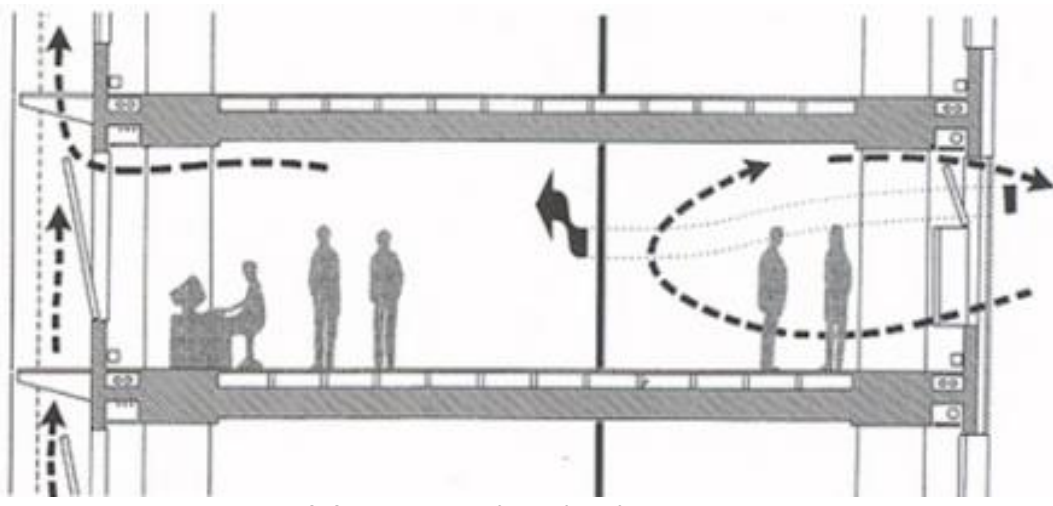

Şekil 3. Çapraz havalandırma sistemi

\subsubsection{Hoberman Arch, Utah, 2002}

Uyarlanabilir sistem: Dönüştürülebilir yapı

Yapı yüke dayanıklı ve hareketli mekanizmadan oluşan en büyük dönüştürülebilir yapı olarak kabul edilmektedir. Dönüştürülebilir yapı, değişen dış ortam koşullarına göre adapte olabilen ve bunu tüm yaşam süresi boyunca yapabilen yapılardır. Günümüz teknolojisi ile bu sistemlerin karşılaştığı zorluklar henüz geliştirilme aşamasındadır.

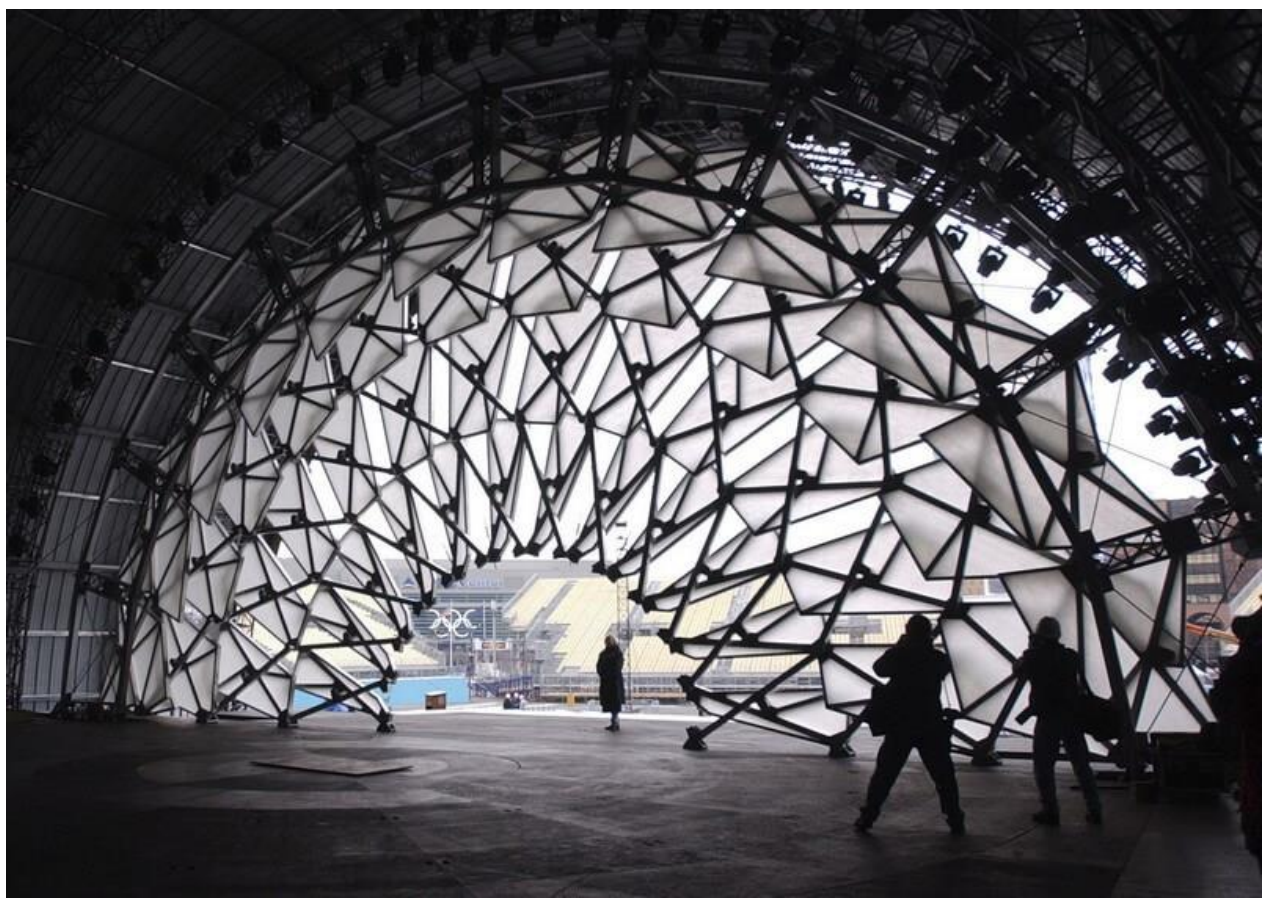

Şekil 4. Hoberman Arch, Detay 
Şekil 4'te görüldüğü gibi 13000 perçin kullanılarak farklı boyutlarda 96 paneli birbirine bağlayan bir sistemden oluşan Hoberman Arch, 4000 ayrı parçadan yapılmıştır.

\subsubsection{Homeo Static Cephe Sistemi, New York, Prototip}

Uyarlanabilir sistem: Dinamik cephe, akıllı malzemeler

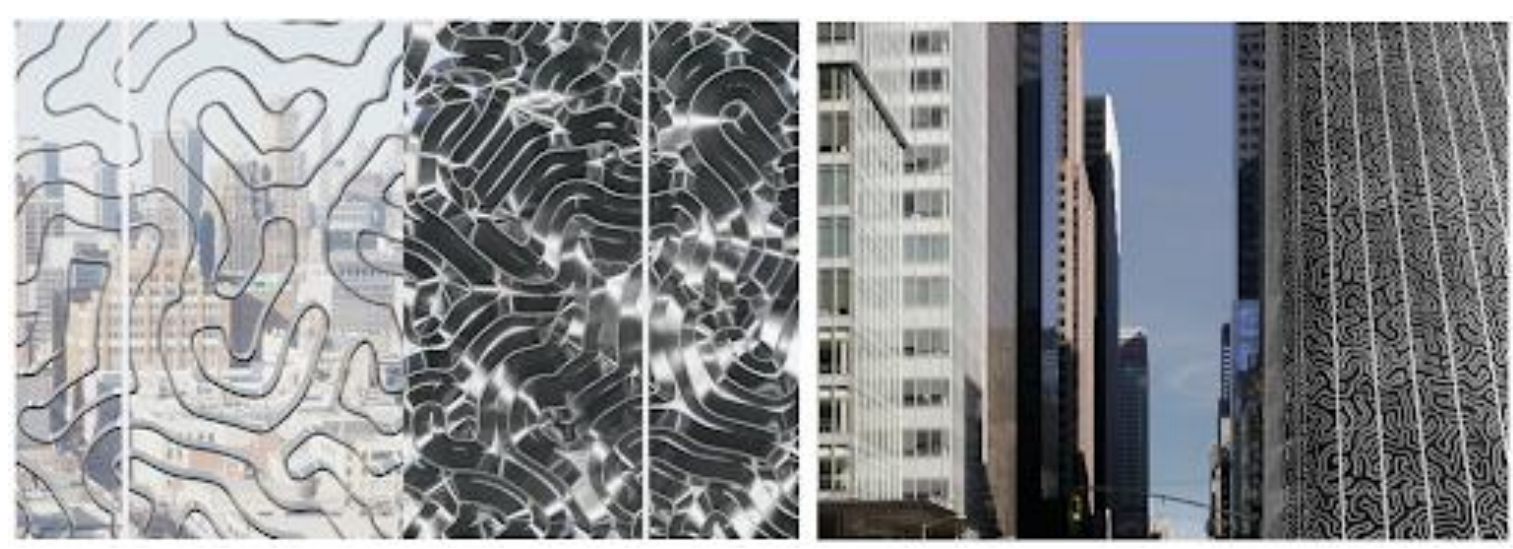

Şekil 5. Homeo Static cephe sistemi

Homeostaz, organizmaların farklı eylemlerle iç koşulları düzenlediği doğal bir fenomen olarak kabul edilip, sıcağa karşı oluşan bir tepkidir. Şekil 5 'te görüldüğü gibi Homeo Static cephe sistemi, güneş enerjisi kazanımlarını kontrol etmesini sağlayan dielektrik elastomerler prensibine dayanmaktadır. Temel prensip olarak yapı cephesi, dış çevre koşullarına tepki vererek iç ortam koşullarını düzenler. Isı, nem ve ışık gibi dış uyaranlara karşı kontrollü olarak değişebilen akıllı malzeme teknolojisindeki ilerleme, cephenin mimari tasarımdaki etkisinde büyük rol oynadığı düşünülmektedir. Gümüş kaplamalı elastomer panjurlar gün ışığına maruz kaldırğında açıı ve güneş olmadığında kapanır. Bu parnjurlar, yüzeyinde gelen gün ışı̆̆ı ile elektrik yükü üretir ve böylece elastomeri harekete geçirir. Böylece, sistem termal akışı kontrol ederek bina iç ortam sıcaklığını düzenler.

\subsection{Dinamik Kontrollü Uyarlanabilir Cephe Mekanizmaları}

Uyarlanabilir gölgeleme sistemleri şekil, genişlik, konum veya özelliklerini aynı anda veya bir zaman dizisinde değiştirebildiği gibi, makro veya mikro ölçekte özelliklerin veya davranışların değişmesine dayanır (Hraska, 2019). Makro ölçeği, bina cephesinin hareketli elemanlarla gölgelendiği anlamına gelir. Mikro ölçek, gölgeleme malzemesinde, gölgeleme etkisini artıran optik ve termofiziksel değişikliklerin meydana geldiği anlamına gelir. Sıcaklığa veya ışık yoğunluğuna olarak değişen kaplamalar örnek olarak verilebilir.

Uyarlanabilir gölgeleme sistemlerin kontrolü manuel veya motorlu olarak tasarlanabilmektedir. Manuel kontrol, iç ortamın standartlaştırılmış parametrelerini ve gerekli enerji tasarrufunu sağlamayacaktır. Uyarlanabilir gölgeleme sistemin en bilinen örneği, mimar Jean Nouvel tarafından tasarlanan ve 1987 'de Paris, Fransa'da tamamlanan Arap Dünyası Enstitüsü'dür (Institut du Monde Arabe). Şekil 6'da görüldüğü gibi mimar, iki cam tabakası arasında kamera objektifindeki perdeler gibi metal unsurlar önermiştir. Elemanlar, merkezi bir bilgisayar kontrolüne bağlı motorlar tarafından kontrol edilir ve 30.000 ışığa duyarlı mekanik kontrol diyaframı bulunmaktadır (Hraska, 2019). Bu gölgeleme cihazının temel görevlerinden biri konforlu bir iç ortam sağlamaktır. Binayı aşırı güneş radyasyonundan koruma açısından, uyarlanabilir gölgeleme sisteminin belirleyici parametresi, sağlayabileceği güneş faktörleri ( $\mathrm{g}$ değerleri) aralı̆ı̆dır. Örneğin, elektrokromik pencere camı için tipik g değerleri aralığı 0.64 (şeffaf durum) ile 0.16 (tamamen karanlık durum) arasındadır. 

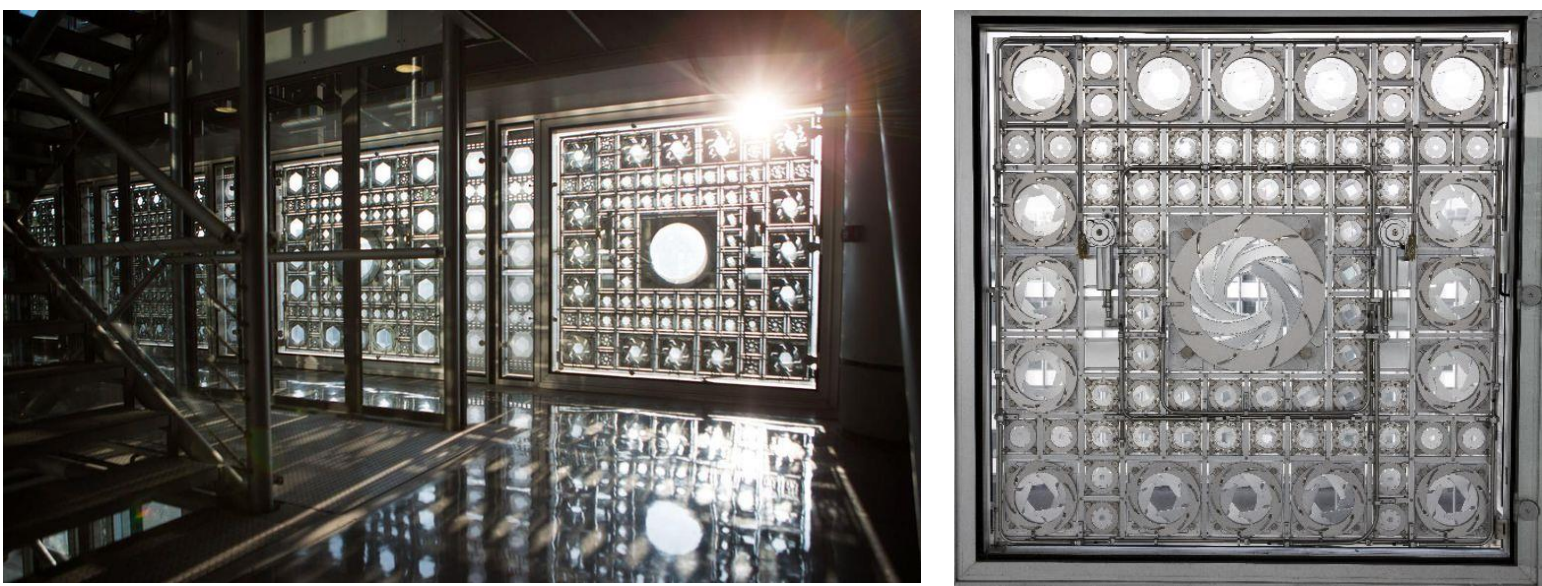

Şekil 6. Paris'teki Arap Dünyası Enstitüsü'nün uyarlanabilir gölgeleme sistemi (Hraska, 2019)

Gölgeleme sistemleri, dış gölgeleme, iç gölgeleme ve entegre gölgeleme sistemleri olarak konumlarına göre sınıflandırılabilir. Uyarlanabilir gölgeleme sistemleri, bir binanın aşırı güneş radyasyonundan korunmasını sağlayan fiziksel / optik işlemlerle sistemleştirilebildiği gibi ışığını yansıtma, soğurma, yönlendirme veya filtreleme gibi kombinasyonlara sahiptir (Hraska, 2019). Diğer gölgeleme sistemlerine akıllı malzemeleri örnek olarak verebiliriz:

- Sıcaklık reaktif malzemeleri (şekil hafızalı alaşımlar, şekil hafızalı polimerler, şekil hafızalı hibritler, termokromik polimerler, termotropik malzemeler, faz değişim malzemeleri (PCM)),

- Güneş radyasyonuna tepki veren malzemeler (ışığa duyarlı polimerler, fotokromik malzemeler, fotovoltaik hücreler),

- Kromojenik malzemeler (elektrokromik camlama, gazokromik malzemeler, sıvı kristaller, asma parçacık cihazları),

- Diğer malzemeler (elektroaktif polimerler, piezoelektrik malzemeler, manyetik özelliklerini değiştiren malzemeler).

Enerji akışı dinamik kontrolü uyarlanabilir bina cephesinde yeniliğin merkezindedir. Gölgeleme elemanlarını bir sensör ağı ve bina enerji yönetim sistem ile entegre ederek en verimli çalışma yöntemi uygulanabilir (Loonen et al., 2015). Bina kabuğunu dinamik ve değişken tasarlamak için, mekanik olarak harekete geçirilmesi, döndürülmesi, genişletilmesi, küçültülmesi, bükülmesi gerekmektedir. Bina cephesinde dört farklı çalıştırma yöntemi vardır: (1) motor tabanlı; (2) hidrolik; (3) pnömatik; ve (4) malzeme bazlı. Otomatik uyarlanabilir cephe sistemlerinin çoğu motor tabanlı, yani mekanik harekete dayanmaktadır. Son zamanlarda, farklı gölgeleme sistemleri oluşturmak için hava geçirmez şekilde kapatılmış hava odalarının şişirilebildiği veya söndürülebildiği çok katmanlı ETFE (etilen tetrafloroetilen) bazlı sistemlerle artan pnömatik çalıştırma kullanımını görülmektedir. Aynı zamanda, büyük ölçekli ticari uygulamalarda, "sıfır enerjili" dinamik bina cephe vaat eden malzeme tabanlı harekete devam eden çalışmalar da vardır.

\subsubsection{Mekanik sistemler}

Motor tabanlı olan çift cidarlı cephelere monte edilen motorlu jaluzi sistemi, dinamik cephelerde kullanılan en yaygın yöntemdir. Parlamayı ve güneş ısısı kazanımını önemli ölçüde azaltabilmektedir. Sauerbruch Hutton tarafından tasarlanan Frankfurt'daki KfW Westarkade iki cam katmanı arasına yerleştirilen panjur sistemine sahiptir (Şekil 7 ve 8). 


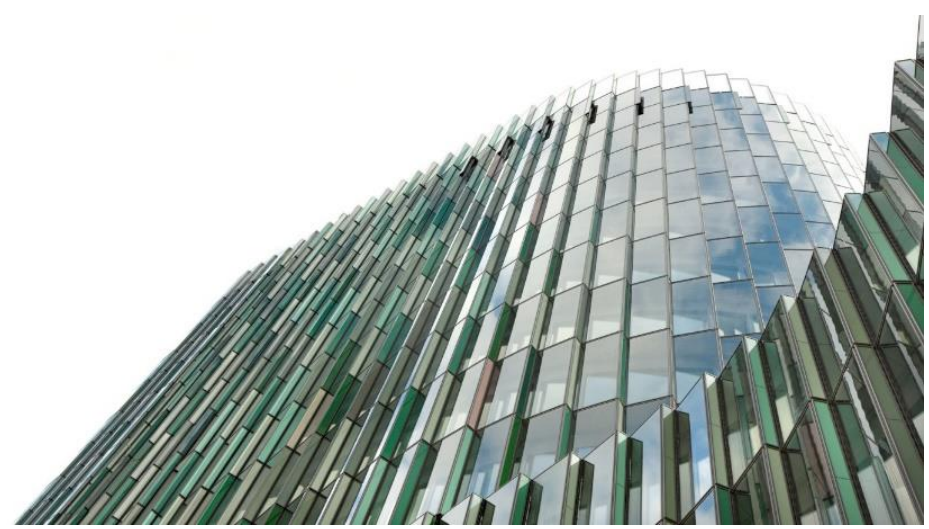

Şekil 7. KfW Westarkade, Sauerbruch Hutton, Frankfurt

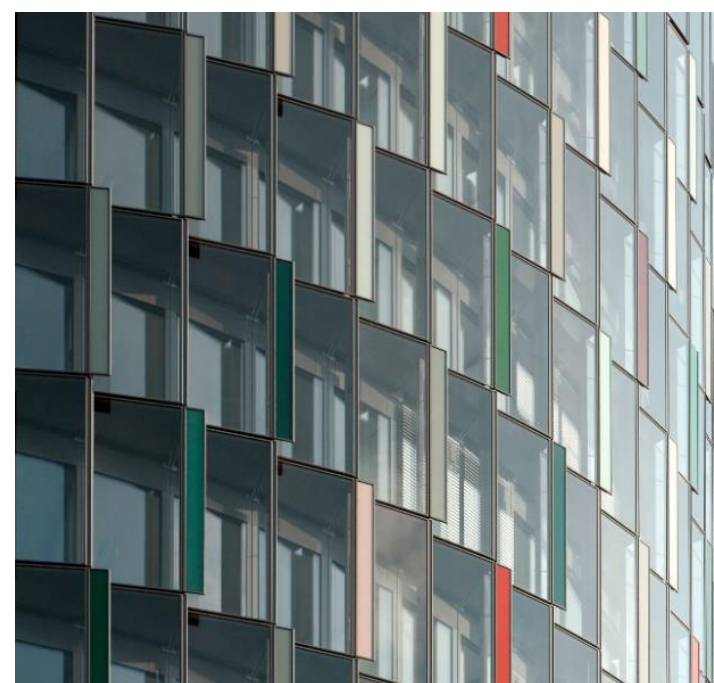

Şekil 8. KfW Westarkade cephe detay

\subsubsection{Hidrolik sistemler}

Hidrolik aktüatörler tipik olarak içi boş bir silindire yerleştirilmiş bir piston içerir (Harry, 2016). Pistona eşit olmayan bir baskı uygulandığında harici bir nesneyi hareket ettirebilen bir kuvvet üretilir. Bu şekilde üretilen mekanik hareket, doğrusal, döner veya salınımlı hareket açısından bir çıktı sağlar. New York'taki REX mimarlık stüdyosu, aşırı güneş enerjisi kazanımına karşı koruma sağlayan ve katlar arasına gömülü boşluklardan hızla dışarı çıkarılarak binanın tüm cephesini gölgeleyen, çapı 15 metre olan güneş koruyucular ile bütünleşen bir medya kulesi tasarımı Şekil 10'da gösterilmiştir (Harry, 2016). Şekil 11 'de görüldüğü gibi Mashrabiya adı verilen bu uygulama sıcak çöl binalarını pasif bir şekilde soğutmak için kullanılan eski bir Arap mimari uygulamasıdır. 


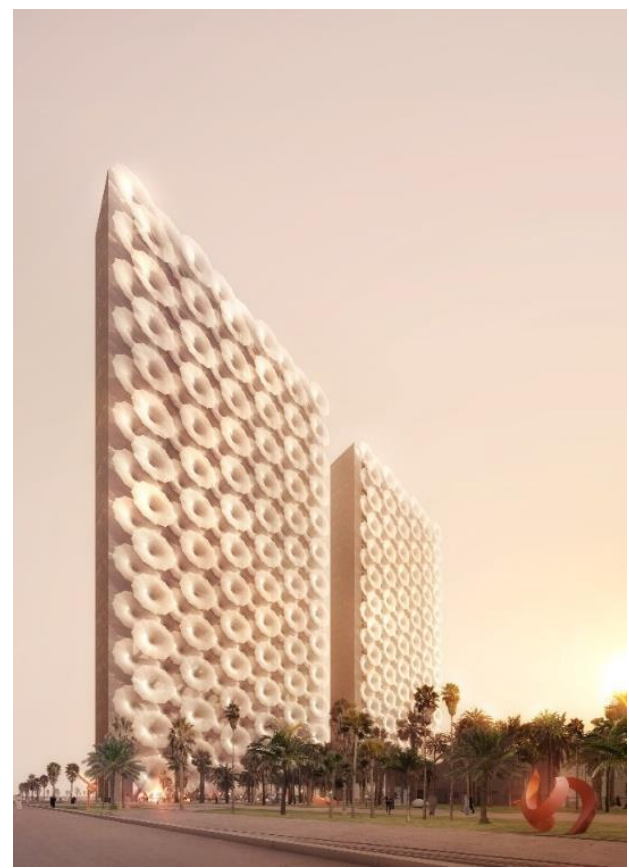

Şekil 10. Orta Doğu medya kuleleri projesi
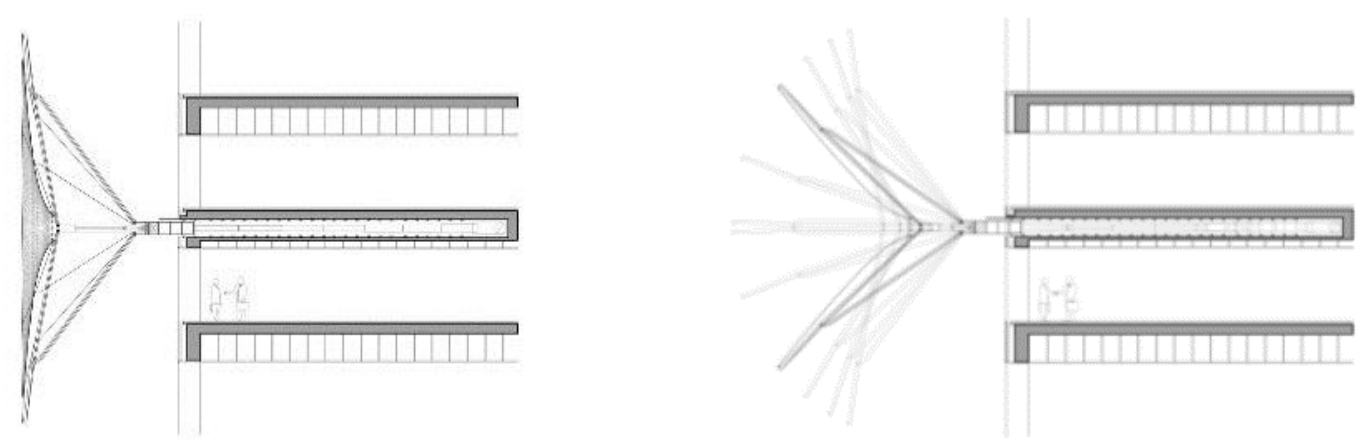

Şekil 11. Mashrabiya gölgeleme elemanlarıyla tasarlanmış cephe

\subsubsection{Pnömatik sistemler}

Modüler Pnömatik Cephe Sistemini (MPFS), basınç altında hava veya gaz pompalayarak hareket ettirmeye dayalı konseptten oluşmaktadır. MPFS, dinamik bir cephe oluşturmak için biyolojik tasarım (örn. sağlamlık ve modülerlik vb.) ve akıllı teknolojinin (örn. Sensör, malzeme, kontrollü çalıştırma) özelliklerini birleştiren kinetik bir cephe sistemidir (Harry, 2016). Bu sistemlere örnek olarak, Barselona'da Enric Ruiz-Geli tarafından tasarlanan ve 2011'de tamamlanan Media-TIC bina tasarımı Şekil 12'de gösterilmektedir. Şekil 13'te görüldüğü gibi yapı, Etilen Tetra Floro Etilenden (ETFE) yapılmış şişirilebilir bir dış yüzeyden oluşmaktadır. Bina, değişen ışıkla genişleyen veya daralan hava odacıklarından oluşur ve bu hareket dijital bir sensör tarafından kontrol edilmektedir. Aynı zamanda kabuk şeffaf bir katmandan oluşurken, şişirildiğinde iç katmanlar için gölgeleme elemanı olarak kullanılmaktadır. Böylece ısı yalıtımını da iyileştirmek gibi bir amacı karşılamaktadır. 


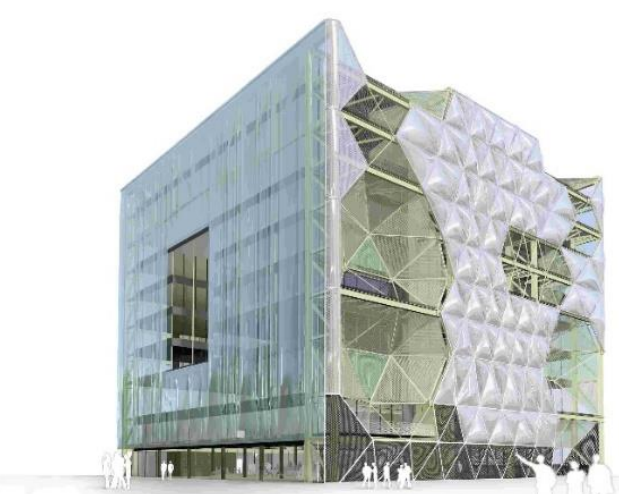

Şekil 12. Media-TIC binası, Enric Ruiz-Geli, Barselona

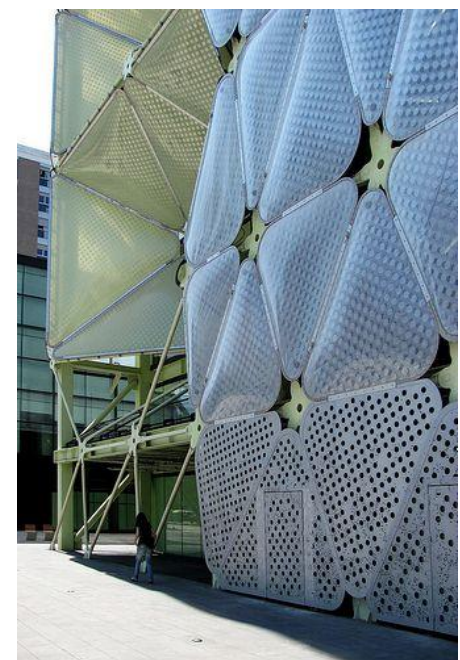

Şekil 13. Media-TIC binası cephe detayı

\subsubsection{Malzemeye dayalı sistemler}

Son yıllarda üretim ve malzeme alanında hızla artan gelişmeler ile algılama ve kontrol mekanizmalarında birçok yenilik ortaya çıkarılmaktadır. Biyolojik sistemlerin işlevselliğini taklit etmek üzere tasarlanmış bu tür malzemeler, birden çok uygulamaya sahiptir (Harry, 2016). Dış uyarana yanıt veren geleneksel malzemelerden farklı olmakla birlikte "akıllı cam" teknolojisi ile değiştirilebilir gözlükler, elektrik akımı uygulandığında (elektro-kromik) veya ısı ve ışık altında (termokromik, fotokromik) dönüştürülebilen camlar ortaya çıkmıştır. Bu akıllı camlar, binaların cephesine monte edildiğinde, aydınlatma, ısıtma, havalandırma ve iklimlendirme maliyetlerini azaltan dinamik kontrollü bina kabuklarını oluşturur ve böylece mekanik olarak çalıştırılan panjur ihtiyacını ortadan kaldırır (Harry, 2016).

\section{Sonuç}

21. yüzyılın sürdürülebilirlik hedefleri doğrultusunda mimari tasarım süreçlerinde malzeme ve sistem tasarımı seçimlerine rehberlik etmek adına uyarlanabilir cephe tasarımı üzerinde araştırmalar giderek artmıştır. Dinamik cephelerin tasarlanması ile ilgili çalışmalar son yıllarda önemli bir araştırma konusu haline gelmiştir. Binaların enerji verimliliğini ve iç mekan konforunu iyileştirmek için cephe tasarımı statikten dinamiğe doğru teknoloji sayesinde dönüştürülmektedir. Bu amaçla, malzeme, bileşen ve sistem bazında farklı türde uyarlanabilir cephe konsepti geliştirilmiştir ve yakın gelecekte ortaya çıkan yenilikçi çözümlerde artış beklenmektedir. Değişken ortam koşullarına adapte olabilen dinamik cepheler, teknolojik gelişmelerin hangi parametreler ile yapı kabuğuna entegre edileceği ve termal koşulların nasıl sağlanabileceği önemli konular haline gelmiştir. Bu makalede, yapının enerji performansını iyileştirmek için uyarlanabilir yapı kabuğu, birçok senaryoya yanıt verecek uygun parametreler doğrultusunda sınıflandıılarak örnekler üzerinden anlatılmıştır. Uyarlanabilir gölgeleme sistemlerinin sınıflandırılma yaklaşımları birçok araştırmacı tarafından farklı kavramlar arasındaki ilişkiyi tanımlaması ile oluşmaktadır. Uyarlanabilir gölgeleme sistemleri, tek başına veya diğer 
sistemlerle etkileşimli olarak tasarlanabilir. Bu makale, doğal havalandırma, gölgeleme teknikleri, enerji tasarrufu ve iç ortamı iyileştirmedeki rolü açısından farklı dinamik uyarlanabilir cephe tekniklerine odaklanmıştır.

\section{Teşekkür ve Bilgi Notu}

Bu çalışmada, dinamik kontrollü uyarlanabilir bina cephesi değişkenlerini sınıflandırarak araştırmalara katkıda bulunulması amaçlanmıştır. Makalede, ulusal ve uluslararası araştırma ve yayın etiğine uyulmuştur. Çalışmada etik kurul izni gerekmemiştir.

\section{Kaynaklar}

Alhazzaa, K. (2019). Contribution of a Passive Dynamic Façade To Energy Reduction, Daylight, and View Quality in a Hot, Arid Climate (Yüksek Lisans Tezi). ProQuest Dissertations and Theses veri tabanından erişildi. Erişim Adresi (2019): https://search.proquest.com/openview/2772ae0afbd2c9eeecb631a14878bc33/

Boer, B. D., Ruijg, G. J., Bakker, L., Kornaat, W., Zonneveldt, L., Kurvers, S., Alders, N., Raue, A., Hensen, J. L. M., Loonen, R. G. C. M. ve Tracka, M. (2011). Energy saving potential of climate adaptive building shells - Inverse modelling of optimal thermal and visual behaviour. Proceeding of the International Adaptive Architecture Conference, 1413-1422. Erişim Adresi: https://www.researchgate.net/publication/254892646/

Ergin, Ö. (2019). Uyarlanabilir Cephe Sistemlerinde Güncel Yaklaşımlar ve Akıllı Malzemelerin Kullanımı (Yüksek Lisans Tezi). Yıldız Teknik Üniversitesi Fen Bilimleri Enstitüsü, İstanbul. Erişim Adresi: https://tez.yok.gov.tr/UlusalTezMerkezi/tezSorguSonucYeni.jsp

Harry, S. (2016). Dynamic Adaptive Building Envelopes - An Innovative and State-of-The-Art Technology. Creative Space. 3(2), 167-184. doi: 10.15415/cs.2016.32004

Hraska, J. (2018). Adaptive solar shading of building. International Review of Applied Sciences and Engineering. s, 9(2), 107-113. doi: 10.1556/1848.2018.9.2.5

Loonen, R. C. G. M., Rico-Martinez, J. M., Favoino, F., Brzezicki, M., Menezo, C., La Ferla, G. ve Aelenei, L. (2015). Design for façade adaptability: Towards a unified and systematic characterization. 10th Conference on Advanced Building Skins (s. 1284-1294). Bern, İsviçre: Economic Forum. Erişim Bilgisi: https://www.researchgate.net/publication/279955723/

Nady, R. (2017). Dynamic Facades: Environmental Control Systems for Sustainable Design. Renewable Energy Sustainable Development, 3(1), 118-127. Online ISSN: 2356-8569. Erişim Bilgisi: https://www.researchgate.net/publication/316615517/

Roy, K. (2018). Adaptive Façade Controls: A Methodology Based on Occupant Visual Comfort Preferences and Cluster Analysis (Yüksek Lisans Tezi). ProQuest Dissertations and Theses veri tabanından erişildi. Erişim Adresi (2018): https://search.proquest.com/openview/62cfc0dd8bfe91cebf8a8fe7b7f852db/ 